\title{
Regional Integration and Real Convergence: Evidence from MENA Countries
}

\author{
Nicolas Péridy \\ Université du Sud Toulon-Var, LEAD \\ Corinne Bagoulla \\ Université de Nantes, LEMNA
}

\begin{abstract}
This article analyses and explains the real convergence process in MENA countries over the past 50 years. It provides a threefold contribution. Firstly, given the recent increasing attention paid to the Euro-Mediterranean area, it focuses on the convergence of MENA countries towards the EU per capita income. Second, it provides an econometric modelling of the determinants of convergence. Finally, it is based on a wide set of convergence indicators applied to various measures of per capita income as well as the Human Development Index (HDI). Results show that despite a lack of s-convergence for the MENA region taken as a whole, the convergence hypothesis is accepted using the $g$ and $\beta$-convergence tests, especially for Tunisia, Egypt, Turkey and Morocco. However, there is evidence of divergence for Jordan and Algeria. It is also shown that the convergence process strongly depends on education, $R \& D$, transport and infrastructure as well as public investment. By contrast, there is no direct impact of the regional integration process with the EU, although the EIB loans positively contribute to the convergence process. Finally, trade specialization and firm agglomeration have been detrimental to convergence of MENA countries.
\end{abstract}

\footnotetext{
*Corresponding address: Nicolas Péridy; Université du Sud Toulon-Var (France), LEAD, UFR Sciences Economiques et Gestion. Avenue de l'Universite, BP 20132, F-83957 La Garde Cedex. Tel : +33 494 142 982. E-mail : nicolas.peridy@univ-tln.fr / Corinne Bagoulla; Universite de Nantes (France), LEMNA, Institut d'Economie et de Management- IAE.

○2012-Center for Economic Integration, Sejong Institution, Sejong University, All Rights Reserved.
} 


\section{-JEL Classification: O47}

- Keywords: Convergence, Growth, MENA Countries, Panel Data

\section{Introduction}

Middle East and North African (MENA) countries have experienced a rather disappointing macroeconomic performance in the past decade, especially when compared with some Asian countries. As an illustration, according to the classification of the World Bank, the average growth rate of these countries reached only $3.8 \%$ in the 90 s and $4.1 \%$ from 2000 to 2009 , whereas at the same time, East Asia and Pacific countries registered respectively $8.5 \%$ and $8.4 \%$ and South Asian countries 5.6\% and 6.5\% (World Bank, 2010). ${ }^{1}$ Within the Euromediterranean area, the growth performance of MENA countries is close to that of EU-15 but well below that of Cohesion countries (Spain, Portugal, Ireland and Greece) before the financial and economic crisis which has started in 2008 (Table 1, Figures 1 and 2). ${ }^{2}$

This modest performance questions the capacity of MENA countries to converge toward EU per capita income levels. ${ }^{3}$ This problem is particularly important since the persistence of huge gaps in the standards of living between the two sides of the Mediterranean is likely to reinforce economic and political problems linked to poverty, illegal migration as well as political instability in these countries as shown by the recent riots in this area.

In this regard, the implementation of the Barcelona Agreement in 1995 was intended to reinforce the economic relationship between the EU and MENA countries, as a means of boosting trade, FDI and also economic growth of these countries. This objective was stated again in the European Neighborhood Policy (ENP) and more recently when the Union for the Mediterranean (UMed) was initiated.

Despite the importance of the concept of real convergence for both the EU and MENA countries, there is currently only a few empirical studies available applied

\footnotetext{
${ }^{1}$ For these data, we used the PPP GDP which is the gross domestic product converted to international dollars using purchasing power parity rates. Data are in constant 2005 international dollars.

${ }^{2}$ This paper disregards the effects of the recent economic crisis on GDP and growth since the period 2008-2011 does not reflect the structural growth pattern of most countries since the 1960s.

${ }^{3}$ In this paper, the concept of real convergence can be defined by the reduction in per capita GDP differences between MENA countries and the EU.
} 
Table 1. GDP per capita growth rates (\%, yearly averages).

\begin{tabular}{lcccccc}
\hline & Constant & PPP & Laspeyres & $\begin{array}{c}\text { Chain } \\
\text { series }\end{array}$ & $\begin{array}{c}\text { GDP chain } \\
\text { p. eq. adult }\end{array}$ & $\begin{array}{c}\text { GDP chain } \\
\text { per worker }\end{array}$ \\
\hline Tunisia & 3,20 & 6,20 & 3,24 & 3,23 & 2,97 & 2,53 \\
Morocco & 2,19 & 6,60 & 2,77 & 2,80 & 2,61 & 2,53 \\
Egypt & 3,10 & 6,09 & 2,76 & 2,73 & 2,61 & 2,41 \\
Israel & 2,82 & 6,19 & 2,55 & 2,48 & 2,37 & 1,77 \\
Turkey & 2,94 & 5,84 & 2,38 & 2,40 & 2,22 & 2,08 \\
Syria & 2,47 & 6,74 & 2,33 & 2,32 & 2,19 & 2,11 \\
EU & 2,50 & 6,36 & 2,28 & 2,31 & 2,16 & 2,06 \\
EU & 2,38 & 6,26 & 2,28 & 2,31 & 2,18 & 2,08 \\
MENA & 2,50 & 5,78 & 2,08 & 2,09 & 1,91 & 1,64 \\
Algeria & 1,44 & 5,81 & 1,31 & 1,34 & 1,13 & 0,78 \\
Jordan & 2,77 & 4,35 & $-0,11$ & 0,03 & $-0,20$ & $-0,48$ \\
\hline
\end{tabular}

Source: own calculations from Heston et al. (2006)

to these countries. Rey (2005), Guétat and Serratino (2006, 2007), Erlat (2007) and Pesaran (2007) concentrate on an analysis of convergence of MENA countries across themselves. This means that the convergence test applies to the income threshold of these countries and not of the EU. Results suggest that the convergence process is not uniform over time and across countries. For example, there may be some differences between oil countries and non oil countries (Rey, 2005), or the existence of convergence clubs as argued by Guétat and Serratino (2007). In any case, the convergence hypothesis is not clearly established for Mediterranean countries.

A few other studies choose another income reference threshold, such as Southern EU countries and France (Guétat and Serratino, 2008, 2009). Using time series tests for income convergence, these authors conclude that there is generally no convergence of MENA countries toward Southern EU countries levels, with the exception of Tunisia and Egypt.

The article presented here complements the studies cited above in several aspects. First, it selects the EU as the reference threshold. The question is thus to assess whether MENA countries have converged towards EU levels, and not toward MENA countries' income long run equilibrium or Southern EU countries' income. This difference may be important because Southern EU countries have experienced higher per capita GDP income growth than the rest of the EU. As a result, MENA countries could have converged toward EU levels without converging toward Southern countries' income. In addition, taking EU countries as 
Figure 1. Trends in GDP per capita growth rates (\%, Laspeyres, yearly averages).

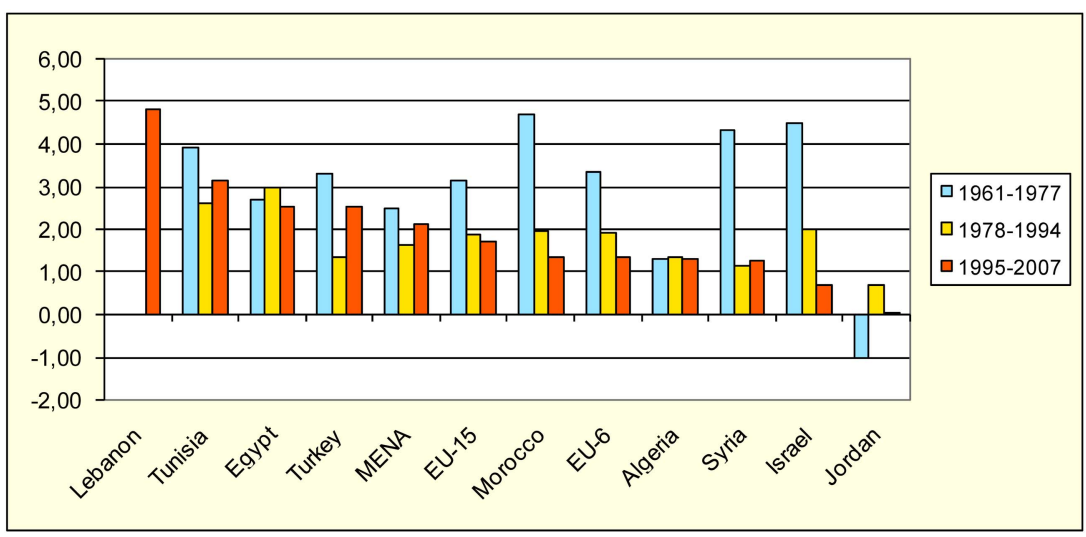

Source: own calculations from Heston et al. (2006)

Figure 2. Trends in GDP per capita growth rates: a comparison with cohesion countries (Laspeyres, \%, yearly averages).

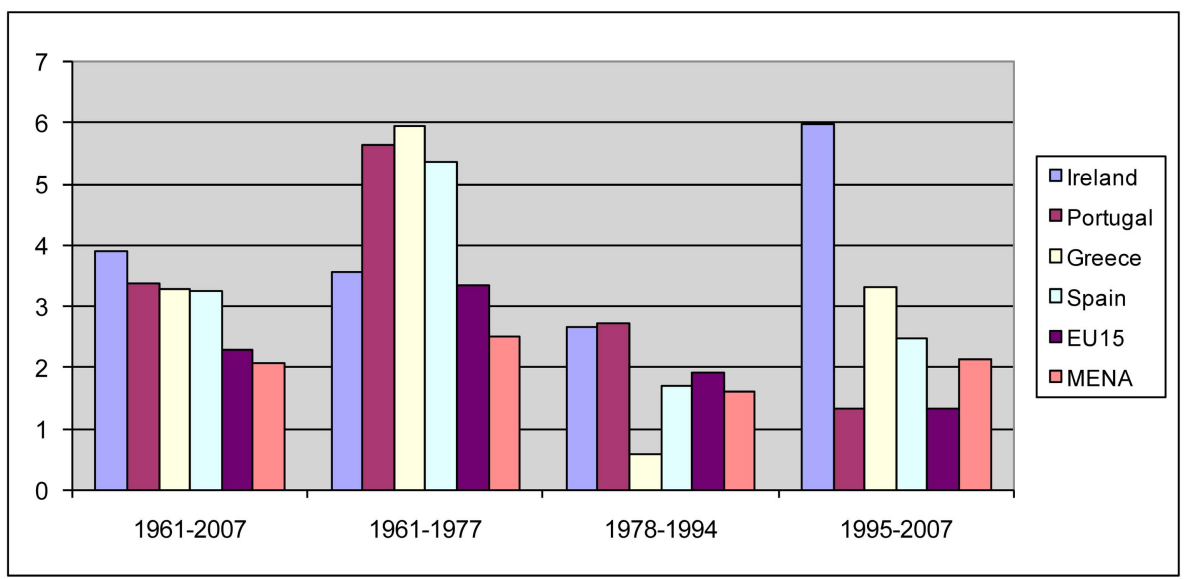

Source: own calculations from Heston et al. (2006)

the reference is particularly relevant with regard to the new developments of the Euro-Mediterranean policy, especially since the Barcelona agreement in 1995.

A second contribution relates to the analysis of the determinants of convergence (or more generally income growth differential between MENA countries and the $\mathrm{EU})$. For that purpose, a panel data econometric model of conditional $\beta$-convergence is implemented, with alternative estimators addressing the endogeneity bias. The impact of R\&D and human capital, trade and openness, economic geography as well 
as transport and infrastructure is tested. In addition, the effects of regional integration are also investigated, especially through the implementation of the Barcelona agreement in 1995 and the European Investment Bank (EIB) loans granted to these countries.

As a final contribution, several convergence indicators are tested. These are not only the traditional $\sigma$ and $\beta$-convergence, but also the $\gamma$-convergence developed by Boyle and McCarthy (1999), based on a Kendall index of rank concordance. Similarly, the analysis does not only focus on convergence of various per capita income indicators (PPP, Laspeyres, chain series, per adult equivalent, per worker), but also on convergence of the Human Development Index (HDI).

This paper is organised in three sections. The first one provides stylized facts about per capita GDP growth in MENA countries. It also analyses the convergence hypothesis through the calculation of various convergence indicators. Section II focuses on modelling the determinants of the per capita income differential between MENA countries and the EU. Section III concludes and discusses the main policy implications of the results.

\section{An Analysis of per Capita GDP Convergence in MENA Countries}

A first insight about convergence within the euro-mediterranean area can be provided by looking at changes in GDP per capita in MENA countries in comparison with the EU. Several country groups can be identified. The first is the EU as a reference group. The EU-6 is first identified as the core reference countries. The EU-15 is also used as an alternative. The selected MENA countries include Algeria, Morocco, Tunisia, Egypt, Jordan, Syria as well as Turkey. Since data for Lebanon are often unavailable, this country is excluded from the Mediterranean country group but data are presented separately when available. Similarly, Israel is considered separately, given the huge gap between GDP per capita in this country and that in the other MENA countries.

Statistics are presented over the period 1960-2007 using yearly averages. ${ }^{4}$ More detailed results are displayed in three sub-periods. The first ranges between 1960 and 1977. It corresponds to the conclusion of the first preferential agreements between the EU and some MENA countries (Association agreements). The second period (1978-1994) corresponds to the implementation of the Global Mediterranean Policy. Finally, 1995-2007 coincides with the period of the

\footnotetext{
${ }^{4}$ When per capita GDP growth is calculated for a country group, this statistic is weighted by the share of each country in the total GDP of its group.
} 
Barcelona agreement.

As a sensitivity analysis, several indicators of GDP are considered alternatively: GDP in US constant price, GDP in purchasing power parity (PPP), the Laspeyres GDP per capita ${ }^{5}$, the chain per capita GDP $^{6}$, the real GDP chain per equivalent adult $^{7}$ as well as the real GDP chain per worker ${ }^{8}$ (Heston et al., 2006).

Tables 1 and Figure 1 report these various statistics. Several major features emerge from them. If we first consider the whole period (1960-2007) (Table 1), it is striking to observe that the per capita GDP growth in MENA countries is very close to that recorded for the EU (EU-6 and EU-15), whatever the GDP indicator used. However, this result masks significant differences across countries. As a matter of fact, countries like Tunisia, Morocco as well as Egypt show per capita GDP growth rates above that of the EU. On the other hand, Algeria and Jordan show growth rates well below the EU average, whereas for Turkey and Syria, it is similar to that of the EU.

Considering changes over time (Figure 1), it is worth mentioning that the EU per capita GDP rate of growth is declining over time whatever the indicator considered. For example, taking the Laspeyres indicator, the rate of growth for the EU-6 declined from $3.35 \%$ in $1960-77$ to $1.91 \%$ in $1978-1994$ down to $1.34 \%$ in 1978-2007 at yearly average. Regarding MENA countries on the other hand, this rate of growth declines first (from $2.51 \%$ to $1.62 \%$ ) before recovering in the last period up to $2.13 \%$. This means that in the first two periods, the MENA rates of growth are generally lower than those recorded for the EU before becoming above that of the EU from 1995 onward.

Again, there are some differences across countries. Tunisia, Turkey and Jordan follow this general declining-recovering trend, whereas Morocco, Egypt and Syria show a declining trend over the whole period. As a result, these differentiated trends modify the ranking of the countries in terms of GDP growth over time. As a

\footnotetext{
${ }^{5}$ It is obtained by adding up consumption, investment, government and exports, and subtracting imports in any given year.

${ }^{6}$ This is a chain index obtained by first applying the component growth rates between each pair of consecutive years, $t-1$ and $t$, to the current price component shares in year $t-1$ to obtain the domestic absorption (DA) growth rate for each year. This DA is then applied backwards and forwards from 1996, and summed to the constant price net foreign balance to obtain the Chain GDP series.

${ }^{7}$ The equivalent measure used here assigns a weight of 1.0 to all persons over 15 , and 0.5 for those under age 15 (refer to Heston et al. (2006) for additional details).

${ }^{8}$ Worker for this variable is usually a census definition based of economically active population. The underlying data are from the International Labour Organization, and have been interpolated for other years.
} 
matter of fact, taking the most recent period (1995-2007), the best performance is recorded for Tunisia and Turkey (increasing trend), still followed Egypt despite its declining trend. These three countries are above the EU average. On the other hand, Morocco moves from above to EU-average (declining trend), Syria moves from above to below EU-average. Algeria and Jordan generally remain below the EU-average.

Considering finally the special cases of Lebanon and Israel, there is some evidence of convergence for Lebanon in the late period (for which data are available). However, these figures must be taken cautiously because of the effects of the war and of the reconstruction of Beirut. With regard to the performance of Israel, it is first above EU averages before moving below.

To sum up, Tunisia is the country which is the most likely to have converged toward EU rates, because its growth rate remains higher than that of the EU whatever the period and whatever the indicator taken into consideration. Turkey and Egypt are also likely to have converged toward EU rates, though their performance is not always above the EU-average depending on the period and the indicator taken into consideration. Morocco is an intermediate case, where the rate of growth was initially above the EU levels, but moved recently to the EU average. Finally, there is no evidence of convergence for Algeria, Jordan and Syria looking at their per capita GDP growth rates.

A final interesting set of statistics relates to the comparison of growth rates with the four cohesion EU members (Greece, Spain, Portugal as well as Ireland) (Figure 2). Over the whole period, it is obvious that these four countries perform better than MENA countries. In fact, only Tunisia approaches these growth rate levels. However, the evolution over time changes this picture to some extent. As a matter of fact, the growth gap between MENA countries and cohesion countries is very significant in the first period. However, this gap is narrowing in the second and last periods. In 1995-2007, the per capita GDP growth in MENA countries becomes greater than that of Portugal and approaches that of Spain (this is particularly true for Tunisia, Morocco, Egypt and Turkey). The gap is only increasing with Ireland, which takes advantage of the growth waves in the financial economy.

Additional information can be provided by specific measures of convergence, which have been improved in the past few years. Indeed, starting with the traditional indicators of convergence, i.e. rank, Gini and Theil indexes, some new concepts have been developed since Sala-i-Martin (1996). The first is $\sigma$-convergence, which states that a group of countries is s-converging if the dispersion of the real per capita 
GDP levels decreases across these countries. It can be defined as:

$$
\sigma=\frac{\operatorname{var}\left(G D P C_{i_{A} t}, G D P D_{i_{B} t}, \ldots, G D P C_{i_{N}}\right) / \operatorname{mean}\left(G D P C_{i_{A} t}, G D P C_{i_{B} t}, \ldots, G D P C_{i_{N} t}\right)}{\operatorname{var}\left(G D P C_{i_{A} 0}, G D P D_{i_{B}}, \ldots, G D P C_{i_{N} 0}\right) / \operatorname{mean}\left(G D P C_{i_{A}}, G D P C_{i_{B} 0}, \ldots, G D P C_{i_{N} 0}\right)}
$$

Where $\operatorname{var}(\mathrm{GDPC})$ and mean(GDPC) refers respectively to the variance and the mean of per capita GDP of countries $\mathrm{i}_{\mathrm{A}}, \mathrm{i}_{\mathrm{B}}, \ldots \mathrm{i}_{\mathrm{N}}$ at year $\mathrm{t}$, using the reference period 0 .

A related concept is $\beta$-convergence. It is derived from the neoclassical growth theory and is based on the idea that if poor countries tend to grow faster than rich ones, there is absolute $\beta$-convergence. More precisely, denoting $y_{i t}$ as the real gross domestic product per capita in country $i$ at year $t$, the linearization of the neoclassical growth model yields to the following absolute $\beta$-convergence specification, often called the Barro regression (Mankiw et al., 1992; Ramajo et al., 2008):

$$
\Delta y_{i t}=\frac{\log y_{i t}-\log y_{i t-1}}{t}=\alpha+\beta \log y_{i t-1}+\varepsilon_{i t}
$$

where $\Delta y_{i t}$ is the annual rate of growth of GDPC. $\alpha$ and $\beta$ are the parameters to be estimated with $\beta=\left(1-\mathrm{e}^{-\theta t}\right) / \mathrm{t}$ and $\theta$ is the rate of convergence to the steady state. In case of convergence, $\beta$ is expected to be negative (the lower the initial GDPC in country $i$, the higher its growth rate, which suggests convergence.

In order to take into account the determinants of growth, equation (1) can be amended by including a set of $\mathrm{k}$ control variables $\mathrm{x}_{1}, \ldots \mathrm{x}_{\mathrm{k}}$, which condition the steady state of each country. This makes it possible to write a second model which can be used for testing conditional $\beta$-convergence:

$$
\Delta y_{i t}=\alpha+\beta \log y_{i t-1}+\gamma_{1} x_{1 i t-1}+\gamma_{2} x_{2 i t-1}+\ldots+\gamma_{k} x_{k i t-1}+\varepsilon_{i t}
$$

The application of the Barro regression to a convergence test concerning MENA countries with regard to the EU GDP per capita threshold can be made as follows. Starting from equation (2) and defining the reference country as the EU-15, the calculation of the absolute $\beta$-convergence between MENA countries and the EU can be implemented by estimating the following equation in panel data econometrics:

$$
\Delta y_{i t}-\Delta y_{E U t}=\alpha+\beta\left(\log y_{i t-1}-\log y_{E U t-1}\right)+\mu_{i}+\lambda_{t}+\varepsilon_{i t}
$$


where $\mu_{\mathrm{i}}$ and $\lambda_{\mathrm{t}}$ are country and time-specific effects, which can be considered as fixed or random depending on the final specification of the model. The calculation of the conditional $\beta$-convergence is left for the next section when investigating the determinants of convergence.

As shown by Quah (1996) and Sala-i-Martin (1996), $\beta$-convergence is necessary but not sufficient for $\sigma$-convergence, while $\sigma$-convergence is sufficient but not necessary for $\beta$-convergence. This implies that the absence of $\sigma$-convergence indicator does not mean that there is no $\beta$-convergence.

Additional insight about convergence can be provided by looking at changes in the income distribution across countries. This concept, referred to as the $\gamma$ convergence, has been introduced by Boyle and McCarthy (1997 and 1999). It is based on the calculation of the Kendall index of rank concordance:

$$
\gamma=\frac{\Delta\left(R y_{t}+R y_{0}\right)}{\Delta\left(R y_{0}{ }^{2} 2\right)}
$$

where Ry is the rank of per capita GDP. This index can be viewed as a complement of the $\sigma$ and $\beta$-convergence. However, the relationship between the $\gamma$ and the $\beta$ convergence is not formally established, although Boyle and McCarthy (1999) suggest that if there is no $\sigma$-convergence, the $\gamma$-convergence measure can be used to ascertain whether the $\beta$-convergence exists.

The remainder of this section focuses on the calculation of these convergence indicators. This analysis is applied to GDP per capita in MENA countries over the period 1960-2007. It is supplemented by an application to convergence of the Human Development Index (HDI).

Looking first at the $\sigma$-convergence, it is striking to observe that over the period 1960-2007, there is some evidence of divergence between MENA countries and the EU. ${ }^{9}$ As a matter of fact, starting from unity, $\sigma$ ranges between 3 and 3.5 in 2007 depending on the GDP indicator used (Figure 3a). ${ }^{10}$ However, it is worth mentioning that despite a continuously increasing value of $\sigma$, a decrease is observed for the first time in the very late period, i.e. from 2001 onward, which is an indication of recent convergence. More detailed information is provided at country level (Figure 3b). Although the evidence of divergence is globally

\footnotetext{
${ }^{9}$ The EU-6 is taken as the reference country group. However, calculations carried out with EU-15 provide similar conclusions.

${ }^{10} \sigma$ is not presented for PPP GDP per capita in Figure 3a. In fact, it follows a more acute upward trend (from 1 to 7.94).
} 
Figure 3. (a) $\sigma$-convergence between MENA countries and the EU.

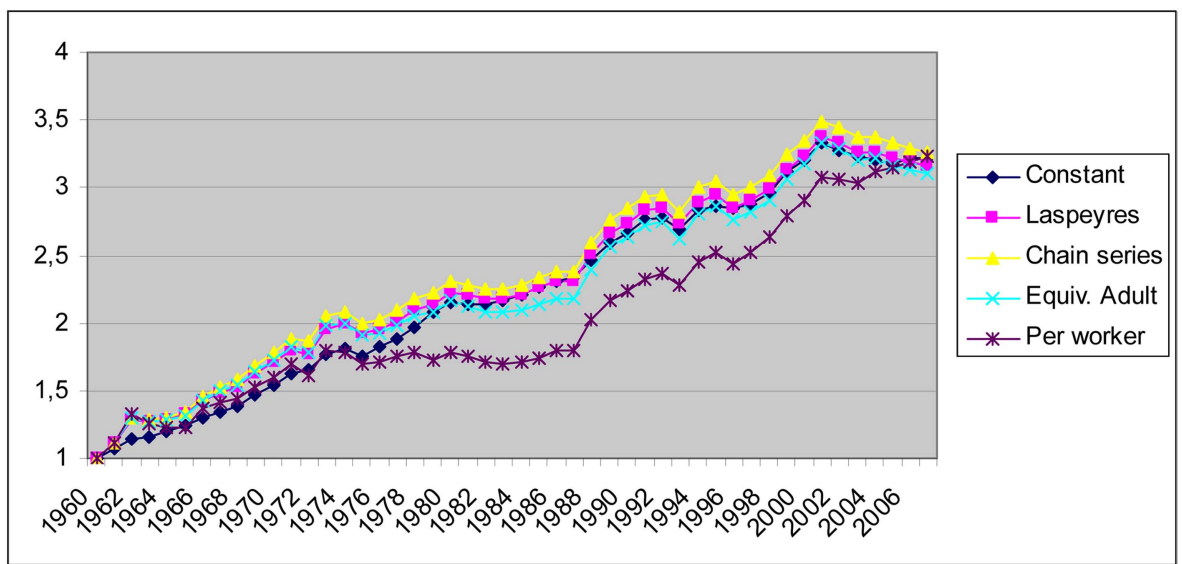

Figure 3. (b) $\sigma$-convergence between MENA countries and the EU (breakdown by country, Laspeyres).

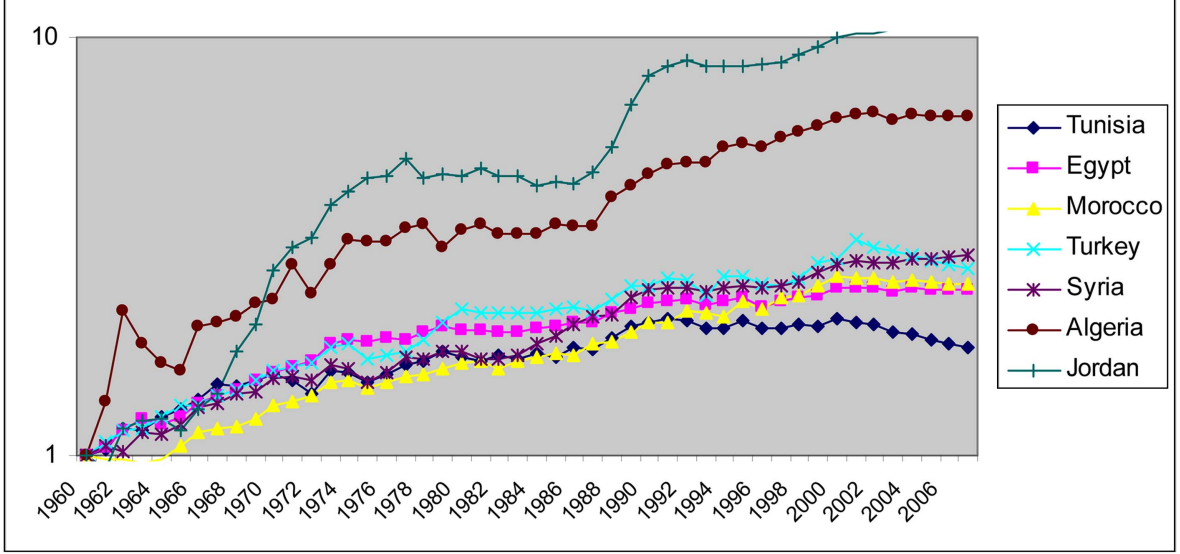

Figure 3. (c) $\sigma$-convergence between Cohesion Countries and the EU (Laspeyres).

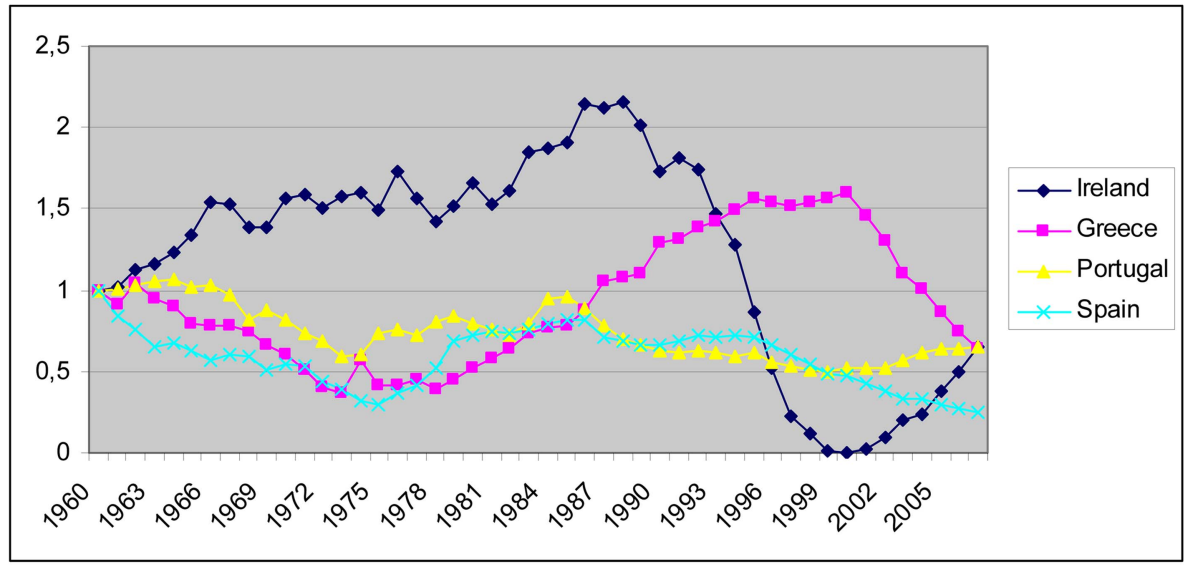


confirmed for all MENA countries, there are significant differences. Tunisia shows the least increasing trend (from 1 to 1.8 over the period) with a significant decrease since 2000 (from 2.1 to 1.8 ). Tunisia is thus the country which has diverged the least. It has even converged in recent years. Turkey follows the same pattern, as well as Egypt and Morocco to a lesser extent. At the other extreme, Jordan, Algeria as well as Syria to a lesser extent experience a continuous and important increase in $\sigma$ over the whole period, even since 2001. For these countries, divergence with the EU is very sharp.

A comparison with the four EU cohesion countries is provided in Figure 3c. With regard to Spain and Portugal, it is striking to observe a strong convergence process since their accession to the EU in $1985 .{ }^{11}$ In recent years, the value of sigma has become very low, especially for Spain (0.25). The convergence of Ireland with EU-6 is even more striking since the late 80s (the value of $\sigma$ reached 0 in 2001). This means that per capita GDP in Ireland reached the EU-6 level. After 2001, $\sigma$ has increased, but in this case, this means that the Irish per capita GDP became higher than the EU-6 one. Greece is the only country for which there is less evidence of convergence during the past 45 years. These results suggest that there is a significant difference in the convergence process of the cohesion countries (generally converging rapidly to EU levels) and MENA countries, which have not $\sigma$-converged to EU per capita GDP. As already mentioned, these figures do not take into account the impact of the recent economic crisis in these countries.

To sum up, the $\sigma$-convergence indicator provides evidence of divergence between MENA countries and the EU, except in recent years for specific countries, such as Tunisia, Turkey as well as Egypt and Morocco to a lesser extent. These results contrast with cohesion countries, especially Ireland, Spain and Portugal which show a rapid convergence process to the EU-6 per capita GDP levels.

However, as already stated previously, the absence of $\sigma$-convergence does not necessarily mean an absence of convergence process. This is why the $\gamma$ convergence indicator, based on the country ranking of per capita GDP, can be used additionally (Boyle and McCarthy, 1999). This indicator has been calculated by looking at changes in the income distribution across 95 countries since 1980. In order to keep the same country group over the period, countries which have

\footnotetext{
${ }^{11}$ This result is supported by specific papers on cohesion countries, such as Barry (2003), Martin and Sanz (2003) as well as Ramajo et al. (2008).
} 
disappeared or new countries have been excluded. ${ }^{12}$ The application of this indicator to the Euro-Mediterranean area complements the previous findings. As a first result, despite a stable or even increasing $\sigma$-convergence indicator, there is some evidence of $\gamma$-convergence between MENA countries and the EU-15, especially since the mid-80s. As a matter of fact, the value of $\gamma$ decreases down to about 0.8 or 0.9 in 2007 depending on the measure of GDP ${ }^{13}$ (Figure 4a). A breakdown by country shows that Tunisia tends to converge (0.56) (Figure $4 b)$. This performance is comparable to that found for Mediterranean cohesion countries (Greece, Spain and Portugal) (see figure 4d). In fact, Tunisia greatly improved its ranking, moving from the $57^{\text {th }}$ to the $43^{\text {rd }}$ position over the period (Figure 4c).

Turkey and Egypt also show a decrease in $\gamma$ since the mid 80s (down to 0.74 and 0.77 respectively). As a matter of fact, Turkey moved from the $54^{\text {th }}$ to the $48^{\text {th }}$ position, whereas Egypt moved from the $64^{\text {th }}$ to the $54^{\text {th }}$ position. Morocco and Syria remain stable around 0.8 all throughout the period, whereas Jordan and Algeria show an upward trend which suggests divergence. Indeed, Jordan moved from the $34^{\text {th }}$ to the $65^{\text {th }}$ rank, whereas Algeria moved from the $36^{\text {th }}$ to the $50^{\text {th }}$ rank.

Overall, compared to the $\sigma$-convergence, the $\gamma$-convergence analysis is generally not supporting divergence. However, the relative performance of the countries is unchanged whatever the convergence indicator used. As a matter of fact, the best performance in terms of convergence is that of Tunisia, followed by Turkey and Egypt. Morocco and Syria are in an intermediate position, whereas Algeria and Jordan are diverging whatever the convergence indicator used.

A last insight can be given through the calculation of $\beta$-convergence. In this regard, the estimation of equation (4) supports the results found with the $\gamma$ convergence analysis. First, there is some evidence of convergence between MENA countries and EU per capita GDP levels, whatever the way GDP is measured and whatever the estimator chosen (Table 2a). This result is also valid whatever the reference countries taken into consideration (EU-6 or EU-15) In this regard, it is worth mentioning that the Hausman test is generally significant. This favours the use of the fixed effects model (FEM).

\footnotetext{
${ }^{12}$ These especially include some Eastern European countries as well as countries included in the former USSR.

${ }^{13}$ However, when GDP is measured per worker, the value remains close to 1 , which does not suggest convergence.
} 
92

Nicolas Péridy and Corinne Bagoulla

Figure 4. (a) $\gamma$-convergence between MENA countries and the EU.

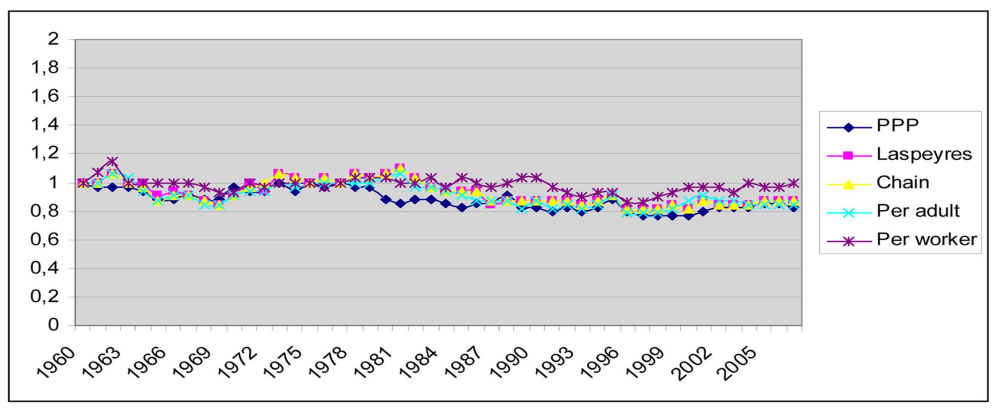

Figure 4. (b) $\gamma$-convergence between MENA countries and the EU (breakdown by country, Laspeyres).

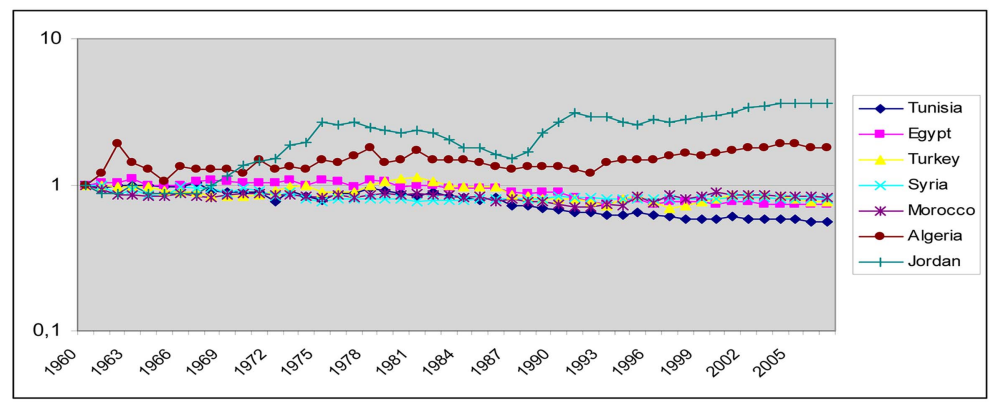

Figure 4. (c) Evolution of country ranking in terms of GDP per capita (1961-1995, yearly, Laspeyres).

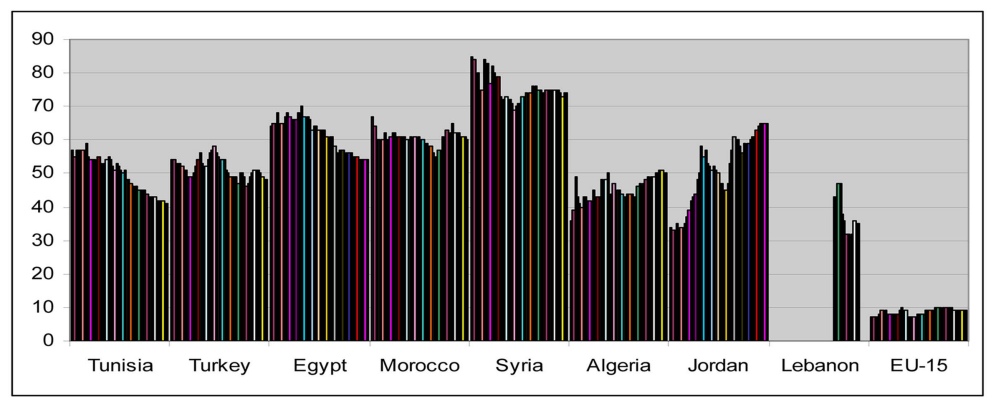

Figure 4. (d) $\gamma$-convergence between Cohesion countries and the EU (Laspeyres).

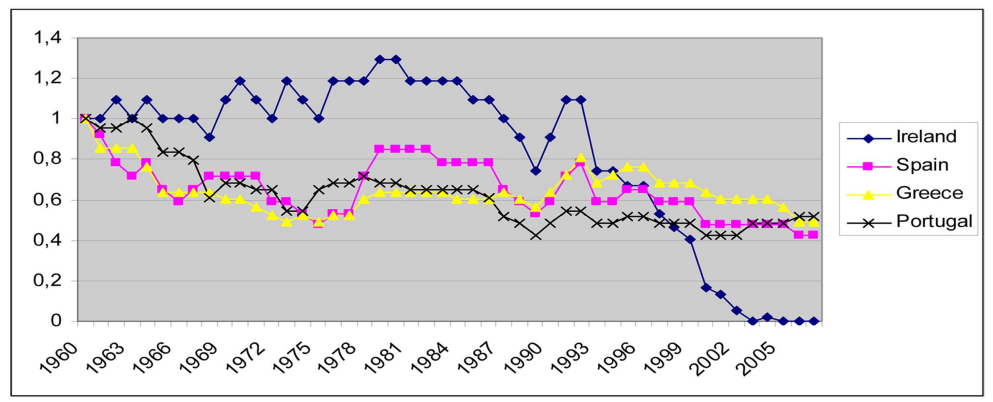


Table 2. (a) $\beta$-convergence between MENA countries and the EU.

\begin{tabular}{lcccc}
\hline & & \multicolumn{2}{c}{ EU-6 } & \\
& OLS & FEM & REM & Hausman \\
\hline GDP constant price & $-1.872^{* *}$ & $-11.348^{* * *}$ & $-1.674^{* *}$ & $17.04 * * *$ \\
GDP PPP & $-2.872^{* * *}$ & $-9.803^{* * *}$ & $-2.674^{* * *}$ & $12.94 * * *$ \\
GDP Laspeyres & $-2.018^{* * *}$ & $-6.183^{* * *}$ & $-1.904^{* * *}$ & $5.75^{* * *}$ \\
GDP chain value & $-2.029^{* * *}$ & $-6.396^{* * *}$ & $-1.896^{* * *}$ & $6.17 * * *$ \\
GDP per adult & $-2.121^{* * *}$ & $-6.026^{* * *}$ & $-2.019^{* * *}$ & $4.99^{* *}$ \\
GDP per worker & $-2.201 * * *$ & $-3.549^{* *}$ & $-2.257^{* * *}$ & 0.74 \\
\hline & & EU-15 & & \\
& OLS & FEM & REM & Hausman \\
\hline GDP constant price & $-1.817^{* *}$ & $-11.082^{* * *}$ & $-1.817^{* *}$ & $16.24 * *$ \\
GDP PPP & $-2.631^{* * *}$ & $-8.711^{* * *}$ & $-2.631^{* * *}$ & $9.66^{* * *}$ \\
GDP Laspeyres & $-1.946^{* * *}$ & $-5.853^{* * *}$ & $-2.587^{* * *}$ & $4.73^{* *}$ \\
GDP chain value & $-1.939^{* * *}$ & $-6.018^{* * *}$ & $-2.493^{* * *}$ & $5.32^{* * *}$ \\
GDP per adult & $-2.031^{* * *}$ & $-5.569^{* * *}$ & $-2.429^{* * *}$ & $4.14^{* *}$ \\
GDP per worker & $-2.120^{* * *}$ & $-3.129 * *$ & $-2.131^{* * *}$ & 0.43 \\
\hline
\end{tabular}

Table 2. (b) $\beta$-convergence between MENA countries and the EU (breakdown by country, Laspeyres).

\begin{tabular}{ccc}
\hline & EU-6 & EU-15 \\
\hline Tunisia & $-37.264 * * *$ & $-37.237 * * *$ \\
Turkey & $-35.627 * * *$ & $-36.903 * * *$ \\
Morocco & $-32.041^{* * *}$ & $-32.722^{* * *}$ \\
Egypt & $-18.442^{* * *}$ & $-19.728^{* * *}$ \\
Syria & $-14.274^{*}$ & $-13.320^{*}$ \\
Algeria & -13.283 & -11.470 \\
Jordan & -4.082 & -3.060 \\
\hline
\end{tabular}

More detailed results at country level indicate that the convergence hypothesis is clearly accepted (at 1\% level) for Tunisia, Turkey, Egypt and Morocco (Table 2b). It is barely accepted for Syria (10\% level) and clearly rejected for Algeria and Jordan.

One last insight about real convergence can be provided by applying the convergence indicators to the HDI. This index is particularly interesting, since it does not only take into account GDP per capita, but also life expectancy and education (literacy rate). As a result, it provides a wider view of a country development convergence process than the GDP per capita only.

The calculation of the $\sigma$-convergence unambiguously concludes that there is a 
HDI convergence of all MENA countries. This conclusion is somewhat different than that previously calculated for GDP per capita. This difference is due to the fact that MENA countries have generally progressed at a greater rate for life expectancy and education than for standards of living. In the 60s for example, life expectancy was generally lower than 50 years for most MENA countries. In 2005, it is always greater than 70 years, whereas in most EU countries during the same period, life expectancy increased by only 10 years, i.e. from 70 to 80 years. More generally, the greater convergence using HDI is expected since this variable and its components are bounded to one.

As a result, the HDI index tended to progress more rapidly in MENA countries than in the EU-6 (Figure 5). As a matter of fact, it moved for 0.54 to 0.73 in MENA countries and from 0.86 to 0.94 in EU-6 countries. ${ }^{14}$ At country level, it is striking to observe that the countries which enjoyed the greatest convergence of GDP per capita are the ones which experienced the greatest convergence in the HDI index,

Figure 5. The Human Development Index (HDI) in Mediterranean countries.

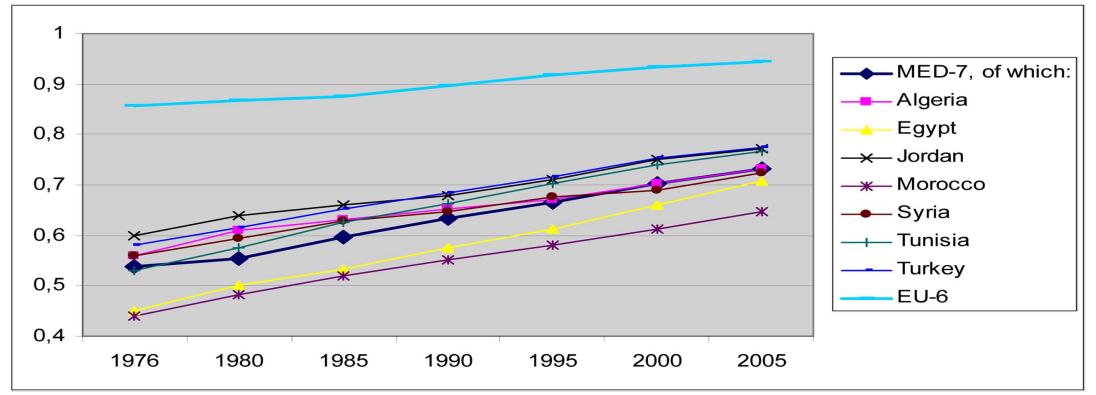

Source: UNCTAD (2009)

Figure 6. $\sigma$-convergence of the HDI between MENA countries and the EU

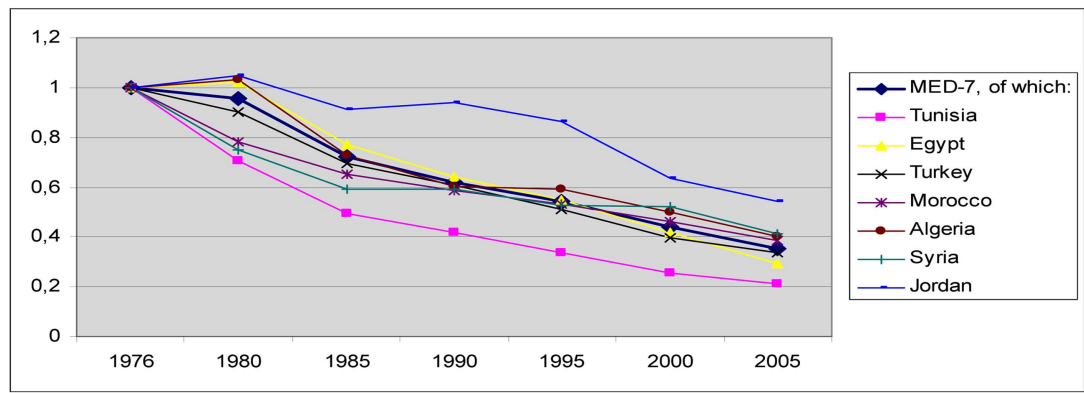

\footnotetext{
${ }^{14}$ Calculations of average HDI in EU-6 or EU-15 provide very close figures.
} 
i.e. Tunisia, Turkey and Egypt. This means that these countries have a better performance than the others in the three components of the HDI. On the other hand, Jordan and Algeria to a lesser extent converge at a slower pace (Figure 6).

Results of the $\gamma$-convergence confirm the previous results, though the evidence of convergence is less established for Jordan and Algeria (Table 3). ${ }^{15}$ Calculations of the $\beta$-convergence between MENA countries and the EU also support the convergence hypothesis, with a $\gamma$-parameter significant at 5\%-level (Table 4).

To sum up, the results obtained at this stage show that despite a lack of $\sigma$ convergence for the MENA region taken as a whole (except when tests are applied to the HDI), the convergence hypothesis is accepted using the $\gamma$ and $\beta$-convergence tests, especially for Tunisia, Egypt, Turkey and Morocco. However, there is evidence of divergence for Jordan and Algeria.

\section{The Determinants of Convergence between MENA Countries and the EU}

This section is aimed at identifying and testing the main variables which explain the convergence (or divergence) process of MENA countries towards EU GDP per capita. Before developing the econometric model, it is useful to provide some stylised facts concerning the factors that may influence growth and convergence.

Table 3. $\gamma$-convergence of the HDI between MENA countries and the EU.

\begin{tabular}{lcccccccc}
\hline \multicolumn{2}{l}{ MED-7, of wh } & Turkey & Tunisia & Egypt & Morocco & Syria & Algeria & Jordan \\
\hline 1980 & 1,00 & 1,00 & 1,00 & 1,00 & 1,00 & 1,00 & 1,00 & 1,00 \\
1985 & 0,98 & 0,93 & 0,96 & 0,98 & 1,00 & 1,05 & 1,00 & 1,03 \\
1990 & 0,98 & 0,86 & 0,96 & 0,98 & 0,98 & 1,17 & 1,07 & 1,08 \\
1995 & 0,92 & 0,84 & 0,94 & 0,96 & 0,98 & 1,23 & 1,14 & 1,05 \\
2000 & 0,96 & 0,84 & 0,94 & 0,95 & 0,96 & 1,05 & 1,05 & 1,00 \\
2005 & 0,92 & 0,79 & 0,82 & 0,91 & 0,93 & 0,98 & 1,02 & 1,03 \\
\hline
\end{tabular}

Table 4. $\beta$-convergence of the HDI.

\begin{tabular}{cccc}
\hline OLS & FEM & REM & Hausman \\
\hline$-2.274^{* *}$ & $0.457^{*}$ & $-2.274^{* * *}$ & 1.11 \\
\hline
\end{tabular}

\footnotetext{
${ }^{15}$ The differences can be explained by the fact that the ranking in HDI is sensitive to the very small differences in HDI levels across two countries which differ for one rank. For this reason, the use of the $\gamma$-convergence seems less reliable when it applies to GDP per capita ranks.
} 
From a pure empirical point of view, Barry (2003) discusses a number of variables which can influence growth and convergence. These are mainly labour productivity, the employment rate, trade openness, research and education, FDI, monetary and fiscal policies, governance and structural funds. However, if the objective is to select and test a relevant set of variables in an econometric model, appropriate techniques must be selected in order to avoid some econometric biases, especially the omitted variable bias. In this regard, Sala-i-Martin (2004) empirically identifies 18 significant variables which determine long-run growth, from a Bayesian Averaging Classical Estimates (BACE) approach. These include first human capital variables, such as education and R\&D. ${ }^{16} \mathrm{~A}$ second set of variables is related to international trade, especially openness, even if the existence of a direct positive relationship between openness (or regional economic integration) and growth is still debated in the empirical literature. ${ }^{17}$ In addition, variables related to patterns of specialization, such as inter-industry specialization and trade dissimilarity are also included. Moreover, the distinction between oil exporters and non oil exporters is established through a specific variable which measures the share of primary products in total exports. Variables related to geography and demography are also expected to have an impact on growth (population density, life expectancy, transportation). The final key variables identified in Sala-i-Martin (2004) refer to additional economic variables (investment price, government consumption, investment share) as well as policy variables (colonization and corruption). Compared to the variables suggested by Barry (2003), Sala-i-Martin (2004) extends the number of variables which can be tested.

In the present analysis, two other sets of variables will be included. The first refers to economic geography, especially agglomeration. Indeed, the impact of firm location and agglomeration in the growth process has been theoretically highlighted first by Krugman (1991). Empirically, this relationship is often mixed. However, it has been shown that this relationship also depends on the type of specialization. Indeed, when countries specialize in (high) low value added products, this can (positively) negatively affect growth and convergence (Amable, 2000).

A final factor which can influence convergence is the use of public funds, like

\footnotetext{
${ }^{16}$ In this regard, it is also interesting to observe that these variables are also introduced in endogenous growth models (Romer, 1990).

${ }^{17}$ For example, refer to Milanovic (2006), Frankel and Romer (1999) as well as Baier et al. (2009) for a survey.
} 
structural and cohesion funds. These funds are accompanying the regional integration process and directly aim to reduce income inequality across regions. For example, Kutan and Yigit (2007) recently showed that in the presence of knowledge spillover effects, cohesion funds lead to more convergence in a regional economic area. More generally, Rodrik et al. (2004) stress the role of institutions as one major determinant of per capita income.

Summing up, the determinants of income convergence depend on various factors, such as return to capital, technology, human capital and knowledge spillover effects, the existence of agglomeration economies, the pattern of comparative advantages and specialization, public capital (especially infrastructure) as well as public policies which can affect the long-run growth through various incentives in terms of capital accumulation, technical innovation as well as the use of structural funds.

Some policy variables are also expected to play a role although they can hardly be quantified. For example, it can be expected that macroeconomic, monetary or fiscal reforms play a role in the convergence process. In this regard, the policy reforms which have been carried out in some MENA countries in the 80s (Morocco and Tunisia) are expected to have made convergence easier since these reforms have significantly contributed to the insertion of these countries in the global economy. In the present research, these reforms are indirectly reflected in the indicators related to openness, FDI and government share in total GDP.

Consequently, the main variables selected here include six groups:

- human capital and technology

- patterns of specialisation and openness (including regional integration and FDI)

- economic geography (agglomeration indexes)

- transportation and communication

- public funds (European Investment Bank (EIB) loans)

- other variables, mainly defined in Sala-i-Martin (2004), such as investment price, government consumption, investment share, population density, life expectancy, colonies as well as corruption.

For each group, several alternative variable measurements are suggested as a sensitivity analysis. The complete description of variables, data and sources can be found in the Appendix. Table 5 provides a statistical overview of the main variables which can explain the growth and convergence process in MENA countries in comparison with the EU. Starting with human capital and technology, there is a 
Table 5. Selected determinants of real convergence.

\begin{tabular}{|c|c|c|c|c|c|c|c|c|}
\hline & Algeria & Egypt & Jordan & Iorocco & Syria & Tunisia & Turkey & EU15 \\
\hline $\begin{array}{l}\text { Education } \\
\text { (secondary schooling rate) }\end{array}$ & 3.2 & 86.2 & 88.7 & 53.4 & 69.6 & 87.0 & 74.3 & 108.8 \\
\hline$\& D(\%$ of GDP) & 16 & 0.19 & 0.35 & 0.80 & 24 & 1.10 & 0.75 & 1.91 \\
\hline penness (trade as a $\%$ of GDP) & 67.4 & 78.7 & 114.6 & 61.6 & 2.8 & 94.4 & 63.4 & 97.1 \\
\hline ts & 99.3 & 84.0 & 69.9 & 75.6 & 75.0 & 43.1 & 52.2 & 45.2 \\
\hline $\begin{array}{l}\text { ter-indu } \\
0 \text { of tota }\end{array}$ & 96.7 & 49.6 & 29.8 & 32.0 & 74.8 & 22.0 & 46.0 & 14.6 \\
\hline Trade diss & 86.6 & 45.6 & 37.3 & 40.7 & 72.0 & 32.5 & 39.0 & 17.0 \\
\hline s) & 0.5 & 0.5 & 1.2 & 10.0 & 0.8 & 4.4 & 2.71 & 6.7 \\
\hline $\begin{array}{l}\text { DI (inward stock, million US } \\
\text { dollars) }\end{array}$ & 11.8 & 71.8 & 14.5 & 32.5 & 9.62 & 6.214 & 5.5 & 6924.3 \\
\hline oads paved ( $\%$ of total roads) & 69 & 78 & 100 & 62 & 60 & 68 & 72 & 93 \\
\hline per 100 people) & 10.1 & 11.4 & 19.7 & 23.7 & 17.4 & 16.8 & 21.0 & 55.9 \\
\hline $\begin{array}{l}\text { Telephone lines } \\
\text { (per } 1000 \text { inhabitants) }\end{array}$ & 79.2 & 159.9 & 148.9 & 83.7 & 103.0 & 164.3 & 305.7 & 567.4 \\
\hline Entropy-specialization index & n.a. & 0.38 & 0.41 & 0.41 & n.a. & 0.66 & 0.28 & 0.18 \\
\hline $\begin{array}{l}\text { Government consumption } \\
(\% \text { of GDP) }\end{array}$ & 22.7 & 10.4 & 52.7 & 18.3 & 29.1 & 13.8 & 14.3 & 18.0 \\
\hline Corruntion indey & 3.0 & 2.9 & 4.7 & 3.5 & 2.4 & 4.2 & 4.1 & 7.7 \\
\hline EIB Loans (million Euros) & 3 & 130 & 50 & 336 & 80 & 389 & 2153 & 34059 \\
\hline
\end{tabular}

Source: refer to Appendix

significant gap between MENA countries and the EU concerning education and R\&D. Interestingly, there are also differences across MENA countries. In this regard, Tunisia, Turkey and Morocco show the best performance in terms of R\&D whereas Algeria, Egypt, Jordan and Syria exhibit very low R\&D/GDP ratio. This may explain part of the differences in the convergence process between Tunisia (and Turkey) and the other MENA countries.

Interestingly, this country classification basically holds for the other variables. For example, regarding variables related to trade and specialization, some countries like Algeria and Syria are characterised by a high share of primary exports, a predominance of inter-industry specialization together with limited openness, a very low share of high-tech exports and a strong trade dissimilarity, i.e. the export structure does not match international demand very well. These trade characteristics are expected to be detrimental to convergence toward EU GDP per capita. On the other hand, some other countries like Tunisia, Turkey as well as 
Morocco, Egypt and Jordan to a lesser extent show different trade characteristics which are expected to be more favourable to their convergence process vis-a-vis the EU.

Infrastructure characteristics seem to be favourable to Tunisia and Turkey as well as Jordan and Egypt. On the other hand, Algeria remains well behind for most indicators (especially the number of internet and telephone users).

The entropy-specialization index also shows significant differences across MENA countries. It shows to what extent production is concentrated in a limited number of industries in comparison to the other countries in the euromediterranean area (refer to Appendix for more details). Tunisia exhibits the greatest value but at this stage, it is not clear that this supports the convergence process. It depends on whether this concentration involves high value-added products. The impact of this variable on convergence will be tested later on.

The last control variables highlight the fact that i) FDI inflows are mainly concentrated in Turkey, Tunisia, Egypt and Morocco. On the other hand, these inflows are very low in Algeria, Jordan and Syria. This low FDI attraction is expected to be detrimental to convergence in these countries; ii) the share of government consumption is significantly higher in Jordan, Algeria and Syria than in the other MENA countries; iii) the corruption index is very detrimental to Syria, Egypt and Algeria; iv) the EIB loans mainly concern Turkey as well as Tunisia and Morocco to a lesser extent.

To sum up, the stylised facts presented above tend to show that the main variables which explain growth are detrimental to Algeria, Syria and Jordan to a lesser extent whereas they seem to be more favourable to Tunisia, Turkey as well as Morocco and Egypt to a lesser extent. These results are consistent with the convergence analysis in the previous section, which showed that Tunisia and Turkey are clearly converging whereas Algeria, Jordan (and Syria to a lesser extent) are diverging.

In a next step, it is important to quantify the impact of these variables in an econometric model in order to check the importance of each variable in explaining the convergence process of MENA countries and the gap with the EU. Starting from equation (3) and (4), the final model of conditional $\beta$-convergence can be written as;

$$
\Delta y_{i t}-\Delta y_{E U t}=\alpha+\beta\left(\log y_{i t-1}-\log y_{E U t-1}\right)+\gamma_{1} x_{1 i t-1}+\gamma_{2} x_{2 i t-1}+\ldots+\gamma_{k} x_{k i t-1}+\mu_{i}+\lambda_{t}+\varepsilon_{i t}(6)
$$


where $\mathrm{x}$ corresponds to a set of control variables described above. ${ }^{18}$ This panel data model is estimated with yearly data from 1960 to 2007 for the seven MENA countries described in the previous section.

For the same reasons as in equations (2) to (4), $\beta$ must be negative to assume convergence. Indeed, the lower GDP per capita in country i relative to the EU, the higher should be its per capita GDP growth compared to the EU.

As a sensitivity analysis, several alternative dependent variables are tested, as in the previous section. They include GDP in US constant price, GDP in purchasing power parity (PPP), the Laspeyres GDP per capita, the chain per capita GDP, the real GDP chain per equivalent adult as well as the real GDP chain per worker (source: Heston et al., 2006). Additionally, the HDI is also included as an alternative dependent variable.

The model developed in equation (6) refers to a conditional growth convergence model $a$ la Barro. In order to select the appropriate control variables, we referred to several empirical studies, especially Sala-i-Martin (2004) as referred to above.

The choice of the appropriate estimators is guided first by the LM test which is significant and consequently rejects the OLS estimator. This means that OLS is biased by the heterogeneity of the data across countries and years. In particular, the Wald test indicates that country-specific effects are significant. ${ }^{19}$ Secondly, the choice of the estimators is guided by the specificity of the dataset, which contains panel data with both time-varying and time-invariant variables. Preliminary estimations are driven with standard fixed effects (FEM) and random effect models (REM). However, given that preliminary Hausman tests on REM indicate the presence of endogeneity problems, the estimator finally selected is Hausman and Taylor (HT). It assumes that some of the explanatory variables are correlated with the individual-level (country i) random effect $\mu_{\mathrm{i}}$. This estimator has been increasingly used in the literature since Egger (2004). The selection of endogenous variables can be done by using both empirical and specific statistical techniques. From an empirical point of view, several variables are suspected to be endogenous.

\footnotetext{
${ }^{18}$ In equation (6), the right-hand side variables $\mathrm{x}$ have been initially tested both with and without differences by the EU value. Results are very similar, mainly because the EU value is the same for each country $i$. As a result, taking the difference for a given variable between each country $i$ and the EU amounts to subtract a constant term. In other words, the model takes into account cross country differences in variables $\mathrm{x}$. This means that if for instance a given MENA country shows a lower openness rate than another MENA country, the model captures to what extent this difference has an impact on the convergence of these two countries with the EU (the corresponding parameter estimate is expected to be positive).

${ }^{19}$ However, time-specific effects are not significant. They are not reported in the tables.
} 
For example, it is likely that infrastructure has an impact on growth but is simultaneously impacted by growth. The same remark also applies to agglomeration, as discussed in the economic geography literature à la Krugman. Finally, the international trade theory also points out the potential endogeneity of trade and openness for explaining growth.

From a statistical point of view, the choice of the variables which are supposed to be correlated with the residuals is guided by the value of the Hausman and Taylor statistic $(\theta)$. The closer $\theta$ to one, the more similar the estimated variance $(\sigma \mathrm{s})$ to the within variance $(\sigma \mathrm{v})$. As a result, the closer the estimated parameters to the within parameters, the smaller the bias due to the correlation of the residuals to the selected independent variables (endogeneity bias). ${ }^{20}$ Consequently, we selected the correlated variables so as to choose a $\theta$-value as close as possible to one. For that purpose, we used a feasible set of instruments, namely the deviation from group means of the time-varying variables, the time-invariant uncorrelated variables, as well as the time-varying uncorrelated variables group means (see detailed computation procedure in Greene, 2003, p.303-306). ${ }^{21}$

As expected, the endogenous variables which have been identified are transport and communication (road, telephone), agglomeration as well as some trade variables (specialisation and openness). ${ }^{22}$ As shown in Table $6 \mathrm{a}$ and $6 \mathrm{~b}$, the Hausman and Taylor statistic is very close to one. This suggests that the HT estimator fairly corrects the endogeneity problem.

As a sensitivity analysis, two other estimators which focus on the endogeneity problem have been used additionally. These are the generalized two-stage least squares instrumental variables estimator (G2SLQ IV) and the error component two-stage least squares instrumental variables estimator (EC2SLQ IV). These differ from the HT estimator since they consider that some independent variables are correlated with the idiosyncratic error $\varepsilon_{\text {it }}$ (not the random effect $\mu_{\mathrm{i}}$ as in HT). Moreover, the method of estimation is also slightly different. The first (G2SLQ IV) has been developed by Balestra and Varadharajan-Krishnakumar (1987). It uses the exogenous variables after they have been passed through the feasible GLS transform. The second one has been developed by Baltagi, where the variables are passed through the Within and Between transform (Baltagi, 2005; Baltagi and Li,

\footnotetext{
${ }^{20}$ For a complete description of this statistic, refer to Egger (2004).

${ }^{21}$ The model is only identified if the number of uncorrelated time-varying variables is at least as large as the number of correlated time-invariant variables.

${ }^{22}$ Education, R\&D and regional integration also contribute to a slight increase in $\theta$, though to a lesser extent.
} 
Table 6a. Estimation results (1960-2007, various estimators, Laspeyre GDP per capita).

\begin{tabular}{|c|c|c|c|c|c|}
\hline & HT & G2SLQ IV & EC2SLS IV & BW GLS & HFGLS \\
\hline initial income level (beta) & $-10.546^{* * *}$ & $-10.550 * * *$ & $-10.549 * * *$ & $-11.8911 * * *$ & $-10.487 * * *$ \\
\hline \multicolumn{6}{|l|}{ Human Capital and Technology } \\
\hline Education & $0.0111 * *$ & $0.0119 * *$ & $0.0111 * *$ & $0.0236^{* *}$ & $0.0123 *$ \\
\hline $\mathrm{R} \& \mathrm{D}$ & $7.549 * *$ & $7.515^{* *}$ & $7.5485 * *$ & $8.2272 * *$ & $7.492 * *$ \\
\hline \multicolumn{6}{|l|}{ Trade, specialization and openness } \\
\hline $\begin{array}{l}\text { Inter-industry specialization } \\
\text { (endogenous) }\end{array}$ & $-1.283 * *$ & $-1.273 * *$ & $-1.273 * *$ & $-1.506^{* *}$ & $-1.270 * *$ \\
\hline Openness (endogenous) & $0.0558 *$ & $0.0560 *$ & $0.0559^{*}$ & $0.0635^{*}$ & $0.0555^{*}$ \\
\hline Endowment in natural resources & $-0.2332 *$ & $-0.2314^{*}$ & $-0.2314^{*}$ & $-0.2780 * *$ & $-0.2305^{*}$ \\
\hline Barcelona agreement (dummy) & 0.183 & 0.228 & 0.229 & 0.008 & 0.183 \\
\hline \multicolumn{6}{|l|}{ Economic geography } \\
\hline Urban (endogenous) & $-0.0042 *$ & $-0.0038^{*}$ & $-0.0038^{*}$ & $-0.0107^{*}$ & -0.0010 \\
\hline \multicolumn{6}{|l|}{ Transport and communication } \\
\hline Road (endogenous) & $2.006^{* *}$ & $1.994 * *$ & $1.995 * *$ & $2.384 * *$ & $1.988^{* *}$ \\
\hline Telephone (endogenous) & $0.0221 * *$ & $0.0211^{* *}$ & $0.0212 * *$ & $0.0253 * *$ & $0.0213 * *$ \\
\hline Internet & $2.5949 * *$ & $2.5799 * *$ & $2.5792 * *$ & $3.0942 * * *$ & $2.5733 * *$ \\
\hline \multicolumn{6}{|l|}{ Other: } \\
\hline government share in consumption & $-0.2714 * *$ & $-0.2712 * *$ & $-0.2712^{* *}$ & $-0.2809 * *$ & $-0.2705^{* *}$ \\
\hline public investment & $0.1603 *$ & $0.1647 *$ & $0.1647^{*}$ & $0.1666^{*}$ & $0.1630^{*}$ \\
\hline investment price & 0.0153 & 0.0156 & 0.0155 & 0.0162 & 0.0156 \\
\hline LM test & $2503 * * *$ & $2503 * * *$ & $2503 * * *$ & $2503 * * *$ & $2503^{* * *}$ \\
\hline Hausman and Taylor statistic (theta) & 0.977 & - & - & - & - \\
\hline Wald test (country) & $39.36^{* * *}$ & $25.17 * * *$ & $25.16^{* * *}$ & $40.12 * * *$ & $41.79 * * *$ \\
\hline
\end{tabular}

1992). In all cases, the estimation is based on instrumental variables and the initial income is used as the instrumented (endogenous) variable. Basically, the variables supposed to be exogenous are the same as those selected in the HT estimator. As shown later, estimation results are also similar. ${ }^{23}$

As alternative estimators, we present the Baltagi-Wu (BW) GLS which assumes a panel autocorrelation of the residuals (Baltagi and $\mathrm{Wu}, 1999$ ), as well as the GLS for heteroskedastic error structures (HGLS) ${ }^{24}$ The choice of these estimators complements the previous ones since they do not particularly focus on the

\footnotetext{
${ }^{23}$ Although the efficiency of the estimators based on instrumental variables is undermined because of the small number of countries considered (seven), our estimation results seem to be robust for two reasons. First because the results are fairly stable whatever the estimator considered (including the standard fixed-effects and random-effects estimators which have been preliminary implemented). Second, as already mentioned, the Hausman/Taylor statistic is very close to unity, which suggests that the endogeneity bias which remains after implementing the HT estimator is very low.

${ }^{24}$ The other standard tests, such as LM, multicolinearity (VIF), omitted variables, etc... have been preliminary implemented and are available upon request.
} 
Table 6b. Estimation results (1960-2007, alternative independent variables, HT estimator).

\begin{tabular}{|c|c|c|c|c|c|c|c|}
\hline & constant & PPP & Laspeyres & chain series & per aduldt & per worker & HDI \\
\hline $\begin{array}{l}\text { initial income } \\
\text { level (beta) }\end{array}$ & $-20.441^{* * *}$ & $-11.782 * * *$ & $-10.546^{* * *}$ & $-10.576^{* * *}$ & $-10.987 * * *$ & $-8.9049 * * *$ & $-32.2502 * * *$ \\
\hline \multicolumn{8}{|l|}{$\begin{array}{l}\text { Human Capital } \\
\text { and Technology }\end{array}$} \\
\hline Education & $0.0187 * *$ & $0.0514 * *$ & $0.0119 * *$ & $0.0113 * *$ & $0.0146^{*}$ & $0.0163 * *$ & $0.0102 * * *$ \\
\hline $\mathrm{R} \& \mathrm{D}$ & $14.065^{* * *}$ & $8.0356^{* * *}$ & $7.515^{* *}$ & $7.705^{* *}$ & $7.719 * * *$ & $6.5772 * *$ & $0.7896 * *$ \\
\hline \multicolumn{8}{|l|}{$\begin{array}{l}\text { Trade, specialization } \\
\text { and openness }\end{array}$} \\
\hline $\begin{array}{l}\text { Inter-industry special- } \\
\text { ization (endogenous) }\end{array}$ & $-1.040 * *$ & $-0.6652 *$ & $-1.283 * *$ & $-1.2393 * *$ & $-1.3117 * *$ & $-1.1900 * *$ & $-0.0682^{*}$ \\
\hline $\begin{array}{l}\text { Openness (endoge- } \\
\text { nous) }\end{array}$ & 0.0055 & 0.0296 & $0.0558^{*}$ & $0.0559^{*}$ & $0.0556^{*}$ & $0.0458^{*}$ & $0.0094 *$ \\
\hline $\begin{array}{l}\text { Endowment in natural } \\
\text { resources }\end{array}$ & $-0.4957 * * *$ & -0.0793 & $-0.2332 *$ & $-0.2153^{*}$ & $-0.2297 *$ & $-0.1864 *$ & $-0.1234 * * *$ \\
\hline $\begin{array}{l}\text { Barcelona agreement } \\
\text { (dummy) }\end{array}$ & 0.439 & 1.399 & 0.183 & 0.286 & 0.155 & 0.126 & 0.187 \\
\hline \multicolumn{8}{|l|}{ Economic geography } \\
\hline Urban (endogenous) & $-0.2598 * * *$ & $-0.0647 *$ & $-0.0042 *$ & -0.0225 & $-0.0354 *$ & $-0.0722 * *$ & $-0.0463 * *$ \\
\hline \multicolumn{8}{|l|}{$\begin{array}{l}\text { Transport and com- } \\
\text { munication }\end{array}$} \\
\hline Road (endogenous) & $2.8776^{* * *}$ & $1.1210^{*}$ & $2.006 * *$ & $1.9214^{*}$ & $2.0331 * *$ & $1.6599 *$ & $0.2343 * *$ \\
\hline $\begin{array}{l}\text { Telephone } \\
\text { (endogenous) }\end{array}$ & $0.0209 * *$ & $0.0112^{*}$ & $0.0221 * *$ & $0.0213 * *$ & $0.0236^{* *}$ & $0.0156^{*}$ & $0.0076^{* *}$ \\
\hline Internet & $4.3601 * * *$ & $1.2084^{*}$ & $2.5949 * *$ & $2.4519 * *$ & $2.6014 *$ & $1.9465^{*}$ & $0.1940 *$ \\
\hline \multicolumn{8}{|l|}{ Other: } \\
\hline $\begin{array}{l}\text { government share in } \\
\text { consumption }\end{array}$ & $-0.3575 * * *$ & $-0.3961 * * *$ & $-0.2714 * *$ & $-0.2907 * *$ & $"-0.2767 * * "$ & $-0.2185^{*}$ & -0.0074 \\
\hline public investment & $0.2716^{* * *}$ & $0.2578 * * *$ & $0.1603 *$ & $0.1982 * *$ & $0.2085 * *$ & $0.2075^{* *}$ & 0.0221 \\
\hline investment price & 0.0224 & 0.0125 & 0.0153 & 0.0116 & 0.0177 & 0.0187 & 0.0017 \\
\hline LM-test & $2501 * * *$ & $2499 * * *$ & $2487 * * *$ & $2503^{* * *}$ & $2501 * * *$ & $2507 * * *$ & $2522 * * *$ \\
\hline Hausman test & 4.25 & 3.94 & 5.55 & 3.33 & 1.88 & 4.40 & 2.22 \\
\hline $\begin{array}{l}\text { Hausman and Taylor } \\
\text { statistic (theta) }\end{array}$ & 0.977 & 0.975 & 0.976 & 0.977 & 0.977 & 0.976 & 0.977 \\
\hline Wald test (country) & $64.26 * * *$ & $39.41 * * *$ & $39.36 * * *$ & $40.25 * * *$ & $39.71 * * *$ & $36.76^{* * *}$ & $38.84 * * *$ \\
\hline
\end{tabular}

endogeneity bias, but make it possible to correct other possible biases (heteroskedasticity and autocorrelation).

Tables $6 \mathrm{a}$ and $6 \mathrm{~b}$ show the results for the model estimated for the whole period (1960-2007), using a) alternative estimators and b) alternative independent variables as a sensitivity analysis. Some secondary variables are dropped from the estimations because they are non significant and introduce multicolinearity problems. These are life expectancy, population density and coastal population 
density, corruption as well as colonization. ${ }^{25}$

Basically, the results are fairly stable whatever the choice of the independent variable and whatever the choice of the estimator. As a matter of fact, the initial income level is always negative and significant at $1 \%$-level. This means that MENA countries are converging to the EU level over the period 1960-2007, conditionally to the other independent variables included in the model. This result correlates with those found with the absolute $\beta$-convergence calculated the previous section.

Some other variables are also very significant. These are first education and R\&D, which both significantly contribute to convergence in MENA countries. Second, transport and communication also play a determinant role for explaining growth and convergence. As a matter of fact, roads (endogenous variable), telephone lines (endogenous variable) and even internet all show a positive and significant sign whatever the estimator.

Trade, specialization and economic geography (which are endogenous) also matter. Indeed, inter-industry specialisation exhibits a negative sign. This means that specialization in MENA countries is detrimental to convergence. This result can be explained by two reasons. The first is that the absence of intra-industry trade reveals the lack of product differentiation and scale economies. Following the new international economics (Krugman, 1995), this deprives MENA countries from important trade and growth gains related to product varieties and lower prices due to scale economies. A second and more important reason is that MENA countries generally specialize in low-value added products, i.e. textile and clothing, fuel products, basic chemicals or agriculture. This type of specialization is less growth creating than specialization in higher value added products (electronics, car industry, etc...). This result is supported by the economic geography variable which is negative. This suggests that the agglomeration of economic activities (measured first by urbanization) is detrimental to convergence because it concerns low value added industries, as stated by economic geography theory. In addition, it is interesting to observe that the variable related to the share of primary exports is also negative. This means that oil producers (Algeria, Syria and Egypt) have diverted their factor resources away from most productive industries. Another

\footnotetext{
${ }^{25}$ The reason for these variables to be insignificant can be found in the restricted sample of the study, i.e. the Euro-Mediterranean area. Sala-i-Martin (2004) uses a worldwide model, which better highlights the impact of these variables, especially because the data sample includes less developed countries (Subsaharian Africa, South Asia, etc...).
} 
interpretation is that the large rents due to oil specialization are associated with more political instability or rent-seeking and low growth (Sala-i-Martin, 2004).

The openness parameter (endogenous) is generally positive and significant. However, the significance level never exceeds $10 \%$ whatever the model specification. This indicates that openness is not a primary variable which explains growth, as is also shown by numerous empirical studies.

The direct impact of the Barcelona agreement is measured in three alternative ways. First, a temporal dummy is introduced in the model (it is equal to unity since 1995 and zero before). In tables $6 \mathrm{a}$ and $6 \mathrm{~b}$, this variable is positive but insignificant. Second, the model has been estimated in two distinct periods, i.e. 1961-94 and 1995-2007. For each model, the $\beta$-convergence parameter is estimated. Results show that this parameter does not significantly differ in these two periods. As a last exercise, the model is estimated by multiplying the initial income variable with a yearly dummy. This makes it possible to estimate a $\beta$ parameter for each year. Again, results show that the $\beta$-parameter is not changing significantly over time. ${ }^{26}$

Amongst the remaining variables, the share of government consumption in GDP has an expected negative sign. This can be explained by the fact that public consumption is financed by distortionary taxes which reduce the growth rate (Salai-Martin, 2004). However, the share of public sector investment in GDP exhibits a positive sign. This result supports the role of public investment in MENA countries, especially concerning transport, infrastructure and technology.

To sum up, Tables $6 \mathrm{a}$ and $6 \mathrm{~b}$ stress the primary role of education, technology, transport and communication as growth determinants. Trade specialization and firm agglomeration play a negative role due to specialization in low value added activities. However, at this stage, there is no evidence that the Barcelona agreement has made a significant impact.

The results presented above are complemented with additional sensitivity analysis. For that purpose, the model is re-estimated with an extended number of variables, used as different proxies for $\mathrm{R} \& \mathrm{D}$, agglomeration, specialization and regional integration. However, since these extended variables are not available for the whole period, the estimation period is restricted to 1995-2007 (Table 7). ${ }^{27}$

\footnotetext{
${ }^{26}$ Detailed results are available from the authors upon request.

${ }^{27}$ As a means of saving space, results are presented by using the Laspeyre GDP per capita as the independent variable. The complete set of results which includes the estimations for the other independent variables is available upon request.
} 
Table 7. Estimation results (1995-2007, alternative dependent variables, HT estimator).

\begin{tabular}{|c|c|c|c|c|c|c|}
\hline initial income level (beta) & $-25.8223 * * *$ & $-19.1627 * * *$ & $-25.0531 * * *$ & $-25.7795 * * *$ & $-47.8599 * * *$ & $-47.1601 * * *$ \\
\hline \multicolumn{7}{|l|}{ Human Capital and Technology } \\
\hline Education & $0.0052 *$ & $0.0172 * *$ & $0.0371 * *$ & $0.0051^{*}$ & $0.3042 * * *$ & $0.3234 * * *$ \\
\hline$R \& D$ & $3.6453 * *$ & & $5.2525 * * *$ & $3.9958 * *$ & $3.9200 * *$ & $2.5675 * *$ \\
\hline Patents applications & & $0.0126 * *$ & & & & \\
\hline \multicolumn{7}{|l|}{ Trade, specialization and openness } \\
\hline $\begin{array}{l}\text { Inter-industry specialization } \\
\text { (endogenous) }\end{array}$ & $-0.4522 *$ & $-0.5922 * *$ & & & $-0.8185^{* *}$ & $-0.8277 * *$ \\
\hline $\begin{array}{l}\text { high tech specialization } \\
\text { (endogenous) }\end{array}$ & & & $0.1291 *$ & & & \\
\hline trade dissimilarity (endogenous) & & & & $-0.4471 * *$ & & \\
\hline Openness (endogenous) & $0.0183^{*}$ & $0.0109 *$ & $0.0171^{*}$ & $0.0173 *$ & $0.2237^{*}$ & $0.2151^{*}$ \\
\hline FDI & 0.0001 & 0.0002 & 0.0003 & 0.0004 & 0.0001 & 0.0002 \\
\hline Endowment in natural resources & $-0.1486^{*}$ & $-0.5442 * *$ & $-0.2005^{*}$ & -0.0802 & $-0.3815^{* *}$ & $-0.3876 * *$ \\
\hline \multicolumn{7}{|l|}{ Economic geography } \\
\hline Urban (endogenous) & $-0.2222^{*}$ & $-0.1347^{*}$ & $-0.1584^{*}$ & $-0.1678^{*}$ & & \\
\hline $\begin{array}{l}\text { specialization (concentration) } \\
\text { (endogenous) }\end{array}$ & & & & & $-9.8046 * *$ & \\
\hline entropy (endogenous) & & & & & & $-7.3959 * *$ \\
\hline \multicolumn{7}{|l|}{ Transport and communication } \\
\hline Road (endogenous) & $1.019 * *$ & $1.9190 * *$ & $1.365 * *$ & $1.083 * *$ & $0.1770 *$ & $0.2049 * *$ \\
\hline Telephone (endogenous) & $0.0952 *$ & $0.0497 *$ & $0.1015^{*}$ & $0.0241^{*}$ & $0.0702 * *$ & $0.0748 * *$ \\
\hline Internet & $1.9844 * *$ & $1.0666^{* *}$ & $0.8959 *$ & $1.8035^{* *}$ & $0.3215^{* *}$ & $0.1719 *$ \\
\hline \multicolumn{7}{|l|}{ Other: } \\
\hline government share in consumption & $-0.6761 * * *$ & $-0.7194 * * *$ & $-0.7082 * * *$ & $-0.6802 * * *$ & $-1.407 * *$ & $-1.6029 * * *$ \\
\hline public investment & $1.2097 * * *$ & $0.9075 * * *$ & $11819 * * *$ & $1.1722 * * *$ & $1.0113 * * *$ & $1.0248 * * *$ \\
\hline investment price & 0.0041 & 0.0055 & 0.0368 & 0.041 & -0.0641 & -0.0666 \\
\hline \multicolumn{7}{|l|}{ Public funds } \\
\hline EIB loans & $0.0051 * * *$ & $0.0059 \div \div$ & $0.0497 * * *$ & $0.0050 * * *$ & $0.0195 * * *$ & $0.0120 * * *$ \\
\hline Hausman test & 4.10 & 6.66 & 5.08 & 4.54 & 4.56 & 5.99 \\
\hline Hausman and Taylor statistic (theta) & 0.977 & 0.981 & 0.976 & 0.981 & 0.977 & 0.980 \\
\hline Wald test (country) & $47.57 * * *$ & $50.74 * * *$ & $47.01 * * *$ & $47.02 * * *$ & $59.57 * * *$ & $59.44 * * *$ \\
\hline
\end{tabular}

Results are the following. First, using the patents applications as an alternative proxy for R\&D provides similar results (positive and significant parameter estimate). Second, the alternative proxies for specialization are significant. As a matter of fact, the high-tech export specialization is positive. ${ }^{28}$ Again, this supports the positive growth impact of high-value added product specialization. Trade dissimilarity presents an expected negative sign, because as trade in MENA countries becomes more dissimilar to that of the EU, it poorly matches

\footnotetext{
${ }^{28}$ This variable is significant at $10 \%$ level because of muticolinearity problems with primary exports and R\&D (inverse correlation). When removing these two variables, the high-tech export variable becomes significant at $1 \%$ level.
} 
international demand.

FDI is also introduced in the model as a complement of trade, specialization and openness but this variable proves to be insignificant. This means that there is no clear direct link between FDI and convergence in MENA countries. Again, it may be that openness and FDI inflows are a necessary but not sufficient condition for convergence. It depends on whether they apply to high-value added products.

The use of alternative economic geography variables support and complement the results found previously. Indeed, when replacing the urbanization index by a concentration index or an entropy variable, these variables have both a significant and negative sign. This reinforces the idea that economic agglomeration in MENA countries has not supported convergence in recent years, because of the low value added of the products involved.

Finally, the indirect impact of the Barcelona agreement is tested by introducing a variable which accounts for EIB loans. This variable is unambiguously positive and significant at $1 \%$. This means that although the convergence rate has not significantly changed since the Barcelona agreement implementation in 1995, the EIB instrument is a useful tool for promoting growth and convergence in MENA countries.

\section{Conclusion and Policy Implications}

This article has shown that despite a lack of $\sigma$-convergence for the MENA region taken as a whole, there is some evidence of $\gamma$ and $\beta$-convergence between MENA countries and the EU, although some countries are not converging, especially Algeria and Jordan.

The analysis of the determinants of convergence revealed that some variables are crucial for explaining the convergence process. These are first education and R\&D. In this regard, it is worth mentioning that some MENA countries have made significant efforts in the past decades. As a matter of fact, the secondary enrolment rate, which was below 50\% in most MENA countries before 1990, has reached in 2005 more than $75 \%$ in Turkey (76\%), Tunisia (83\%), Egypt (86\%), Jordan (88\%) as well as Algeria (83\%). Significant progress has also been made in Syria and Morocco, although this rate is still below $70 \%$ in these countries. This progress must be pursued in the coming years in order to reach the $100 \%$ rate of developed countries.

Similarly, given the importance of R\&D for explaining growth, MENA 
countries should go on investing in this field. Some countries have already made significant progress in recent years, especially Tunisia, Turkey and Morocco. In these countries, the R\&D expenditures approach $1 \%$ of GDP. This is close to the levels reached in Southern EU countries, but still far from those in France and Germany (greater than 2\%) as well as Sweden and Finland (more than 3.5\%). However, Algeria, Egypt, Jordan and Syria exhibit rates which are lower than $0.35 \%$. These countries should make considerable efforts in the coming years to improve their research capacity as a means of bridging the GDP per capita gap with the EU. These efforts primarily rely on governments' priorities with regard to education and public research. In addition, private research can be encouraged through fiscal incentives or public subsidies.

MENA countries should also continue to invest in transport and communication. For instance, Turkey, Tunisia, Jordan and Morocco have significantly improved their roads and developed highways and other transport infrastructure. These countries (including also Egypt) have also considerably improved telephone access, with more than 100 telephone lines per 1000 inhabitants. The internet access is also progressing. As a matter of fact, in 2005, Morocco has counted 24 internet users for 100 people, Jordan 23, Tunisia 17. However, these countries still remain far from EU levels (generally greater than 50 users per 100 people). As a result, investments in this area must be a priority. This remark applies particularly to Algeria, Egypt and Syria which generally show a wider gap with EU levels. These investments can be either private or public depending on the type of infrastructure or communication (private mobile phone and internet networks, public road networks, etc...).

MENA countries should also increase their efforts to open their economies even if

Table 8. basic demographic indicators (2000).

\begin{tabular}{lccc}
\hline & $\begin{array}{c}\text { Total population } \\
\text { of growth (\%) }\end{array}$ & $\begin{array}{c}\text { Natural rate of } \\
\text { growth (\%) }\end{array}$ & Migration rate (\%) \\
\hline Algeria & 1,47 & 1,52 & $-0,05$ \\
Egypt & 2,00 & 2,04 & $-0,04$ \\
Jordan & 3,10 & 2,36 & 0,74 \\
Morocco & 1,74 & 1,86 & $-0,12$ \\
Syria & 2,58 & 2,58 & 0,00 \\
Tunisia & 1,08 & 1,15 & $-0,07$ \\
Turkey & 1,60 & 1,52 & 0,08 \\
\hline
\end{tabular}

Source: US Census 
openness and FDI are not sufficient conditions for growth. This can be achieved by the governments through WT0 negotiations, the conclusion of regional agreements as well as appropriate domestic reforms related to trade (reduction in NTBs, introduction of international technical standards or certification procedures, etc.).

Changes in the specialization and the agglomeration processes are more difficult to achieve directly, since these processes do not directly depend on government decisions and policies. Still, the development of education and R\&D and more generally human capital may be helpful for changing this process.

Finally, it has been shown that the Barcelona agreement has not made it possible to directly stimulate convergence. However, the EIB loans have significantly contributed to convergence. As a result, these loans must be encouraged and developed, especially for projects in line with human capital, transports and infrastructure. The contents of the Barcelona program should also be reconsidered in the light of the Union for the Mediterranean so as to include more growthcreating projects.

As a final point, some countries still face detrimental demographic and migration indicators (Table 8). The case of Jordan is particularly significant. Indeed, the population in this country has increased much more than in the other MENA countries, i.e. from 3 to 6 million inhabitants since 1990. This is due to both higher natural increase and also the inflow of foreign population after the two Gulf wars (especially from Iraq). As a consequence, in order to maintain the same growth in per capita GDP as the other MENA countries, this country needs to attain considerable GDP growth. Although economic theory does not directly relate population growth to standards of living, Jordan is likely to be negatively affected by population growth, partly due to the inflow of migrants. Syria and Egypt also face high growth rates (more than $2 \%$ each year) though it is not due to migration. Still, these countries should also accelerate their efforts to control population growth and migration flows when necessary, through appropriate policies or incentives.

Received 14 June 2011, Revised 15 January 2012, Accepted 20 January 2012

\section{References}

Amable, B. (2000), "International Specialisation and Growth", Structural Change and Economic Dynamics, 11, 413-431. 
Baier, S., J. Bergstrand and P. Egger. (2009), "The Growth of Regional Economic Integration Agreements and the Middle-East", Région et Développement, 29, 11-30. Baltagi, B. (2005), Econometric Analysis of Panel Data, New York: Wiley, $3^{\text {rd }}$ edition Baltagi, B. and Q. Li. (1992), "A Note on the Estimation of Simultaneous Equations with Error Components", Econometric Theory, 8, 113-119.

Baltagi, B. and P. Wu. (1999), "Unequally Spaced Panel Data Regression with AR(1) disturbances, Econometric Theory, 15, 814-823.

Balestra, P. and J. Varadharajan-Krishnakumar. (1987), "Full-Information Estimations of a system of Simultaneous Equations with Error Component Structure", Econometric Theory, 3, 223-246.

Barry, F. (2003), "Economic Integration and Convergence Processes in the EU Cohesion Countries", Journal of Common Market Studies, 41(5), 897-921.

Boyle, G. and T. McCarthy. (1997), “A Simple measure of $\beta$-Convergence, Oxford Bulletin of Economics and Statistics, 59(2), 257-264.

Boyle, G. and T. McCarthy. (1999), "Simple Measures of Convergence in Per Capita GDP: A Note on Some Further International Evidence, Applied Economics Letters, 6, 343-347

Egger, P. (2004), "On the problem of endogenous unobserved effects in the estimation of gravity models", Journal of Economic integration, 19(1), 182-91.

Erlat, H. (2007), "Time Series Approaches to Testing Income Convergence in MENA countries", in: Topics in Middle Eastern and North African Economies", Proceedings of the Middle-East Economic Association, 9, 355-378.

Frankel, J. and D. Romer. (1999), "Does Trade Cause Growth?”, American Economic Review, 89(3), 379-399.

Gallup, J., A. Mellinger and J. Sachs. (2001), "Geography Database”, Center for International Development, Harvard University, www2.cid.harvard.edu/ciddata / geographydata.htm.

Greene W. (2003), Econometric Analysis. New York: Prentice-Hall International. 5th edition.

Guétat, I. and F. Serranito. (2006), Convergence des Revenues au Sein de la Région MENA: une Approche par les Tests de Racines-Unités sur Données de Panel, in : $\mathrm{M}$. Catin and H. Régnault (eds) Le Sud de la Méditerranée face aux Défis du LibreEchange, Paris : l'Harmattan, pp.79-109.

Guétat, I. and F. Serranito. (2007), "Income Convergence within MENA countries : A Panel Unit Root Approach", Quarterly Review of Economics and Finance, 46: 615706.

Guétat, I. and F. Serranito. (2008), "Convergence des Pays de la Région MENA vers le niveau de Revenue des Pays du Sud de l'Europe ", Document de Recherche CEPN, 2008/17, Université Paris-13, France.

Guétat, I. and F. Serranito. (2009), "Convergence et Rattrapage Technologique : Un Test par les Séries Temporelles dans le Cas de Pays de la Région MENA », Conference DREMM CNRS, UMR 7170, Istanbul, 21-23 May. 
Heston, A., R. Summers and B. Aten. (2006), Penn World Table Version 6.2, Center for International Comparisons of Production, Income and Prices at the University of Pennsylvania.

Krugman. (1991), Geography and Trade, Cambridge, MA: MIT Press

Krugman, P. (1995), "Increasing Returns, Imperfect Competition and the Positive Theory of International Trade”, in: G. Grossman (ed), Handbooks in Economics, vol. 3. Amsterdam; New York and Oxford: Elsevier, North-Holland, pp.1243-1277.

Kutan, A. and T. Yigit. (2007), "European Integration, Productivity Growth and Real Convergence", European Economic Review, 51, 1370-1395.

Mankiw, G., D. Romer and D. Weil. (1992), "A Contribution to the Empirics of Economic Growth", Quarterly Journal of Economics, 111-407-434.

Martin, C. and I. Sanz. (2003), "Real Convergence and European Integration: The Experience of the Less Developed EU Members", Empirica, 30, 205-236.

Milanovic, B. (2006), "Economic Integration and Income Convergence: Not Such a Strong Link?" Review of Economics and Statistics, 88(4), 659-670.

Pesaran, M. (2007), “A Pair-Wise Approach to Testing for Output and Growth Convergence", Journal of Econometrics, 138, 312-355.

Quah, D. (1996), "Empirics for Economic Growth and Convergence", European Economic Review, 40, 1353-1375.

Ramajo, J., M. Marquez, G. Hewings and M. Salinas. (2008), "Spatial Heterogeneity and Interregional Spillovers in the European Union: Do Cohesion Policies Encourage Covergence across Regions?" European Economic Review, 52, 551-567.

Ray, S. (2005), “Convergence Réelle et Convergence Nominale dans les Pays de la Région MENA, FEMISE Report 22-36, Obstacles to South-South Integration, to trade and to foreign direct investment: the MENA countries case "ch.4, pp.194-248.

Rodrik, D., A. Subramanian and F. Trebbi. (2004), "Institution Rules: The Primacy of Institutions over Geography and Integration in Economic Development", Journal of Economic Growth, 9, 131-165.

Sala-i-Martin. (1996), "The Classical Approach to Convergence Analysis", Economic Journal, 106, 1019-1036

Sala-i-Martin. (2004), "Determinants of Long-Term Growth: A Bayesian Averaging of Classical Estimates (BACE) Approach", American Economic Review, 94(4), 814-835.

UNCTAD. (2009), World Development Indicators, 2008.

Wodon, Q. and S. Yitzhaki. (2006), "Convergence Forward and Backward?", Economics Letters, 92, 47-51.

World Bank. (2010), World Development Indicators 2010.

\section{Appendix: Measurement, data and sources.}

\section{Human capital and technology:}

- Education: it is measured by the secondary schooling enrolment rate. Source: 
WDI (2008)

- Technology: Two proxies are defined to account for technology (Source: WDI 2008)

- Research and Development expenditures as a percentage of GDP

- Patents applications, resident and non resident (data from 1985 to 2007)

\section{Trade, specialization and openness}

- Pattern of specialization. Following Amable (2000), two alternative variables are used to capture the impact of specialization on convergence:

- Inter-industry specialization: $I_{j}=\frac{1}{2} \sum_{i}\left|\frac{X_{i j}}{X_{. j}}-\frac{M_{i j}}{M_{. j}}\right|$ with $0<\mathrm{I}_{\mathrm{j}}<1$

The higher $\mathrm{I}_{\mathrm{j}}$, the more trade balances are dissimilar across industries, and then the higher inter-industry trade (source: own calculations from UNCTAD, 2008, Handbook of Statistics)

- Trade dissimilarity: $A_{j}=\frac{1}{2} \sum_{i}\left|\frac{X_{i j}}{X_{. j}}-\frac{M_{i}}{M_{. .}}\right|$with with $0<\mathrm{A}_{\mathrm{j}}<1$

The higher $A_{j}$, the less the export structure of country $j$ matches international demand (the more trade is dissimilar). This is expected to negatively affect growth, since in this case, trade patterns of country $\mathrm{j}$ is at odds with that of international demand. (source: UNCTAD, 2008, Handbook of Statistics)

- Openness. It is calculated in two alternative ways:

- Trade in goods and services as a percentage of GDP at current price (WDI 2008) and Heston et al. (2006)

- Trade in goods and services as a percentage of GDP at constant price (Heston et al. (2006))

- Regional integration: dummy which accounts for the various regional agreements between the EU and Mediterranean countries, especially the Barcelona agreement in 1997.

- FDI: flows and stocks in million US dollars. Source: UNCTAD, World Investment Report, 2008 (data from 1970 to 2007)

- Endowment in natural resources: primary exports as a percentage of total exports. Source: UNCTAD 2009 (Comtrade)

\section{Economic Geography variables:}

- Agglomeration: The sign is expected to be negative for countries which are 
specialised in low value added products, like MENA countries. However, it can be positive for other countries, since the agglomeration of firms of industry $i$ in country $j$ leads to a rise in productivity and thus a rise in wages and growth.

- Concentration (specialisation index): We denote first $X$ as the variable of interest (output), $i$, the industry and $j$, the country and $t$, the year.

Defining Sijt as the specialization ratio at industry-level:

$$
S_{i j t}=\frac{X_{i j t}}{X_{j t}}
$$

And

$$
S_{i t}=\frac{\sum_{j} X_{i j t}}{\sum_{i} \Sigma_{j} X_{i j t}}
$$

With $X_{i t}=\Sigma_{j} X_{i j t}$ and $X_{j t}=\Sigma_{i} X_{i j t}$

Thus, the specialization (concentration) index is equal to:

$$
D_{j t}=\sum_{i}\left|S_{i j t}-S_{i t}\right|
$$

It measures to what extent the shares of the various industries $i$ in country $j$ output differ from those in the other countries (data from 1980 to 2003 from UNCTAD, INDSTAT 2008)

- Entropy-specialization index. As an alternative, this index is based on the Balassa location index $L_{j t}$, which measures the ratio of industry i's production to country j's total output, corrected by the ratio of country j's production to that of the whole Euro-Mediterranean area (data from 1980 to 2003 from UNCTAD, INDSTAT 2008)

$$
E_{j t}=\Sigma_{i} S_{i j t} \ln \left(L_{i j t}\right)
$$

- Urban: people living in areas defined as urban in each country, as a share of total population. Source: World Bank, Global Development Network Growth database

\section{Transportation and Communications}

- transportation: roads paved as a percentage of total roads (source: WDI 2008);

- communications: 
- telephone lines per 1000 inhabitants (Source: World Bank, Global Development Network Growth database)

- internet users (per 100 people, source: WDI 2008).

\section{Public funds:}

European Investment Bank loans: EIB Group, Annual Report, various issues (data from 1996 to 2007)

\section{Other factors:}

- Investment price: price level of investment expenditure basket on PPP basis. Source: Heston et al. (2006) (the related coefficient is expected to be negative, since a relative initial high price reduces future possible income growth).

- Government consumption: share of government consumption in GDP. Source: Heston et al. (2006). A negative sign is expected because public consumption is financed by distortionary taxes which reduce the growth rate. It is alternatively measured either as a percentage of GDP in PPP (Heston et al. 2006), as a percentage of gross domestic income in PPP (Heston et al. 2006) or as a percentage of constant GDP (WDI).

- Investment share: public-sector investment as a share of GDP (negative sign expected) (Heston et al. (2006). It is measured either as a percentage of GDP in PPP or as a percentage of gross domestic income in PPP (Heston et al. 2006).

- Coastal population density: share of population in costal area. Source: Gallup et al. (2001) (expected positive sign)

- Population density. Source: WDI 2008 (positive sign expected).

- Life expectancy (at birth in total years). Source: WDI 2008 (positive sign expected)

- Colonies : Source: Gallup et al. (2001)

- Corruption. It is measured by the Transparency International Corruption Perception index (2008). The index defines corruption as the abuse of public office for private gain and measures the degree to which corruption is perceived to exist among a country's public officials and politicians. It is a composite index, drawing on 14 polls and surveys from 12 independent institutions, which gathered the opinions of businesspeople and country analysts. Since this index ranges from zero (highly corrupted) to 10 (no corruption), an increase in this index denotes a reduction in corruption. Thus, a positive sign is expected. 